\title{
MULHERES E A APROPRIAÇÃO DO LUGAR DE AUTORIA NO PIAUÍ NO FINAL DO SÉCULO XIX E PRIMEIRAS DÉCADAS DO SÉCULO XX
}

\author{
Olívia Candeia Lima Rocha \\ Saulo Cunha de Serpa Brandão
}

Resumo: O final do século XIX e as primeiras décadas do século XX foi um período de transição na sociedade brasileira, caracterizado por transformações de caráter social, político e cultural. Nesse contexto, as mulheres se apropriaram da escrita de caráter público, na imprensa e na literatura, e utilizavam esses veículos de comunicação como forma de reivindicar a ampliação da atuação feminina na sociedade. Esse texto procura refletir sobre o processo de apropriação feminina dos lugares de autoria, utilizando como fontes textos publicados em periódicos como Borboleta (1906); O Piauí (1926) e as obras Flores Incultas (1875) de autoria de Luiza Amélia de Queiroz e Fases do meu passado (1983) de Lili Castelo Branco. Essa análise se pautou em autores como Michel Foucault, Nicolau Sevcenko e Norma Telles que auxiliaram na percepção da literatura como um espaço de prestígio e poder, sobretudo, no período em questão.

Palavras-Chave: Mulheres. Imprensa. Literatura. Feminismo. História do Piauí.

\begin{abstract}
The end of the XIX century and the first decades of the XX century was a period of transition in Brazilian society, characterized by social, political and cultural transformations. In this context, women appropriated public writing, in the press and literature and used these vehicles of communication as a form of claming the expansion of female participation in society. This text we seek to reflect the process of female appropriation of places of authorship, using as sources texts published in periodicals like Borboleta (1906); Piaui (1926) and the works Flores Incultas (1875) by Luiza Amélia de Queiroz and Fases do meu passado (1983) by Lili Castelo Branco. This analysis was based on theorists Michel Foucault, Nicolau Sevcenko and Norma Telles who helped in the perception of literature as a space of prestige and power, especially in the period in question.
\end{abstract}

Keywords: Women. Press. Literature. Feminism. History of Piaui. 


\section{INTRODUÇÃO}

As mulheres, em sua maioria, foram historicamente excluídas do acesso à instrução e dos lugares de poder no espaço público. A concepção sobre o papel da mulher na sociedade e sobre a instrução feminina começou a ser modificada no Brasil no século XIX. Entretanto, havia pouca oferta de cadeiras no ensino público destinadas ao ensino de primeiras letras às mulheres. $O$ investimento na educação feminina era custeado principalmente pelas famílias de maior poder aquisitivo, o que significa que nesse período apenas uma parcela reduzida de mulheres tinha acesso à instrução formal.

No final do século XIX, a educação começou a ser valorizada como um fator de progresso nacional. Esta perspectiva de caráter positivista atribuía às mulheres um papel fundamental na formação dos filhos, futuros cidadãos da pátria. Nas últimas décadas do século XIX, verificase o surgimento de vários periódicos e obras produzidas por mulheres que defendiam a ampliação da atuação feminina na sociedade, através do acesso à instrução e da participação política.

Este texto discute a relação entre as transformações culturais no final do século XIX e nas primeiras décadas do 
século XX e a apropriação dos lugares de autoria na imprensa e na literatura pelo sexo feminino, a partir da experiência de algumas mulheres que viveram e publicaram textos no Estado do Piauí no período mencionado ou que retratam a época assinalada, como a publicação Fases do meu passado (1983), obra de caráter memorialista, produzida por Lili Castelo Branco e que se reporta aos limites impostos às mulheres que pretendiam publicar textos na imprensa nas primeiras décadas do século XX.

Para essa reflexão, utilizamos também textos publicados nos periódicos Borboleta (1906) e O Piauí (1926) e obras de autoria feminina, como Flores Incultas publicado em primeira edição no ano de 1875, por Luiza Amélia de Queiroz. A análise realizada procurou levar em conta as dificuldades enfrentadas pelas mulheres para publicar seus textos e o uso da escrita como forma de expressão de seus anseios e, ao mesmo tempo, a produção de novas configurações para a atuação feminina na sociedade no período em questão.

\section{ROMPENDO SILÊNCIOS: MULHERES, ESCRITA E FEMINISMO}

A primeira instância de aproximação das mulheres com a palavra escrita se realizou no âmbito do espaço privado. Nesse sentido, Perrot (1998) destaca que na sociedade francesa do século XVIII, as mulheres eram responsáveis 
pela correspondência epistolar. Através das cartas, as mulheres mantinham os laços de comunicação e de proximidade familiar. Era uma atividade realizada no espaço privado, mas que aproximava as mulheres da escrivaninha e introduzia-as no escritório do ambiente familiar, que até então era reservado ao sexo masculino.

No século XIX, a atividade literária era uma prática que privilegiava a atuação do sexo masculino. Como observa Scott (1995), as relações de gênero são social e culturalmente construídas em relação a um horizonte histórico que atribui características específicas para homens e mulheres. As configurações de gênero da época reservavam aos homens a primazia da atuação no espaço público. Além disso, havia um discurso que distinguia homens e mulheres em uma perspectiva de oposição binária. Afirmava-se que as mulheres eram mais emotivas e os homens mais racionais. Atribuindo-se, assim, uma suposta superioridade intelectual ao sexo masculino.

Escrever obras literárias demandava aprimorada capacidade de racionalidade e inventividade. Ou seja, não era uma ação circunscrita entre as atividades atribuídas ao sexo feminino. Dessa forma, deve-se considerar que as mulheres precisaram transpor fronteiras sociais e culturais 
para se posicionar como autoras de textos de ampla circulação na esfera pública.

Conquistar espaços de expressão discursiva significava, para as mulheres, afirmar-se intelectualmente. Segundo Sevcenko (1999), no final do século XIX e início do século XX, a cultura letrada ganhava contornos de atividade prestigiada que se difundia no Brasil a partir de uma influência europeia, fornecedora de modelos de modernidade e comportamento.

Destaca-se que a palavra escrita se inscreve como um dos mecanismos de expressão dos discursos. O discurso, como observa Foucault (1996), é um instrumento de poder que pode ser utilizado para classificar, segregar e produzir distinções no mundo social, além de projetar realidades possíveis em relação a um dado contexto social. Dessa forma, considera-se que os discursos e os lugares de enunciação podem ser apropriados como meios de reivindicação de novos direitos pelas mulheres. Ao analisar textos de autoria feminina, é necessário identificar a expressão de questionamentos, procurando perceber que lugares sociais que essas mulheres desejavam ocupar. Essas ações podem ser analisadas no contexto do movimento feminista, que para Duarte: 
[...] poderia ser compreendido em um sentido amplo, como todo gesto ou ação que resulte em protesto contra a opressão e a discriminação da mulher, ou que exija a ampliação de seus direitos civis e políticos, seja por iniciativa individual, seja de grupo. Somente então será possível valorizar os momentos iniciais desta luta - contra os preconceitos mais primários e arraigados - e considerar aquelas mulheres, que se expuseram à incompreensão e à crítica, nossas primeiras e legítimas feministas. (2003, p. 152)

Duarte (2003) também destaca o século XIX como o período de surgimento das primeiras manifestações feministas na sociedade brasileira, com escritoras como Nísia Floresta Brasileira Augusta, pseudônimo de Dionísia Gonçalves Pinto (1810-1885), natural do Rio Grande do Norte. Nísia Floresta é considerada a primeira escritora feminista do Brasil, por defender a instrução feminina através de seus textos e iniciativas como educadora. No decorrer do século XIX, surgiram escritoras em diversos estados do país, além de uma variedade de jornais produzidos por mulheres, os quais contribuíram para conferir visibilidade à produção de autoria feminina.

No final do século XIX e início do século XX, os principais papéis atribuídos às mulheres eram os desempenhados junto à família, enquanto filha, esposa e mãe, às quais 
deviam ser obedientes, discretas e solícitas. Nesse período, sobressaiu-se o papel da mulher na educação dos filhos; tratava-se de uma elaboração que opunha a imagem da mulher virtuosa às mulheres "decaídas" (TELLES, 2000). Essa reformulação do papel feminino na sociedade propiciou a emergência de discursos favoráveis à educação feminina, como forma de prepará-las melhor para desempenhar as funções que eram destinadas ao sexo feminino.

A declamação, os bailes e a leitura passaram a fazer parte da sociabilidade e do lazer de famílias de classe alta e média nos centros urbanos da época. Entretanto, a educação feminina pautava-se principalmente no aprendizado de prendas domésticas. Dessa forma, mesmo entre as famílias de elevado poder aquisitivo, era significativo o número de mulheres que não dominavam os códigos de leitura e escrita (FALCl, 2000).

Em um período em que a maior parte da população vivia no espaço rural, a valorização da educação formal ocorria de forma paulatina, como meio de reprodução da condição social, política e econômica da família. Dessa forma, alguns dos filhos do sexo masculino poderiam ter acesso ao ensino secundário e superior, o que lhes propiciava acesso a carreiras como a medicina, a advocacia e a política. As 
profissões e carreiras relacionadas ao espaço público eram culturalmente atribuídas ao sexo masculino (LOURO, 2000; CASTELO BRANCO, 2005).

A principal perspectiva para a vida feminina era o casamento. As mulheres aprendiam noções de leitura e escrita, mas não era esperado que elas desempenhassem atividades no mundo público. Elas deveriam se projetar socialmente pela beleza e pelo desempenho dos papéis de esposa e mãe dedicada. Assim, as que ousavam transpor as prescrições estabelecidas para seu sexo, enfrentavam a censura da sociedade da época, e muitas vezes da própria família. No século XIX, a criação e a autoria eram lugares negados ao feminino:

Mesmo assim, foi a partir dessa época que um grande número de mulheres começou a escrever e publicar, tanto na Europa quanto nas Américas. Tiveram primeiro de aceder à palavra escrita, difícil em numa época em que se valorizava a erudição, mas thes era negada educação superior, ou mesmo qualquer educação a não ser a das prendas domésticas; tiveram de ler o que sobre elas se escreveu, tanto nos romances quanto nos livros de moral, etiqueta ou catecismo. A seguir, de um modo ou de outro, tiveram de rever o que se dizia e rever a própria socialização. Tudo isso tornava difícil a formulação do eu, necessária e anterior à expressão ficcional. (TELLES, 2000, p. 403) 
No século XIX, a educação pública era incipiente, portanto, o investimento na instrução dos filhos era um empreendimento familiar. As famílias de melhor poder aquisitivo recorriam a mestres-escolas, professores particulares contratados pelos pais, por um período determinado e que exerciam seu ofício de forma ambulante, deslocando-se entre fazendas (COSTA FILHO, 2006). Esta era uma forma de ministrar as primeiras letras aos filhos e filhas de famílias que viviam em fazendas no sertão nordestino, como ocorreu, por exemplo, com a escritora piauiense Luiza Amélia de Queiroz, que, segundo Chaves (1994), teve acesso a uma instrução rudimentar e aperfeiçoou seus conhecimentos por esforço próprio.

Luiza Amélia de Queiroz nasceu em 26 de dezembro de 1938, no município de Piracuruca - PI, filha de Manuel Eduardo de Queiroz e Vitalina Luiza de Queiroz. Faleceu em 12 de dezembro de 1898. Luiza Amélia publicou as obras Flores Incultas em 1875 e Georgina ou os efeitos do amor em 1898, adotando uma atitude transgressora, em uma sociedade que considerava a prática literária inadequada à atuação feminina. O livro Flores Incultas foi reeditado pela Academia Piauiense de Letras em 2015. O que tem permitido a leitura e releitura desta obra na contemporaneidade. 
A poesia significava para Luiza Amélia de Queiroz uma forma de escrita de si. A autora abordava em suas poesias acontecimentos e sentimentos vivenciados em seu cotidiano. Além disso, apontava o registro de datas, dedicatórias e comentários, o que faz com que Flores Incultas também possa ser compreendido como um diário poético. A autora vivia na cidade de Parnaíba, situada na região litorânea do Estado do Piauí, que na época possuía um significativo caráter comercial, pois servia de porto de entrada para mercadorias importadas, dentre os quais menciona-se partituras e livros (REGO, 2010).

A situação financeira favorável contribuiu para que Luiza Amélia de Queiroz tivesse acesso à instrução e a clássicos literários, bem como condições de publicar seus livros. O número de mulheres instruídas era reduzido em uma sociedade com um grande contingente de analfabetos e na qual a voz feminina tinha poucas possibilidades de expressão pública. Luiza Amélia de Queiroz apresenta, nas primeiras páginas de Flores Incultas, a poesia "Não sou poeta", da qual destaca-se o trecho a seguir:

Não sou poeta! que ambição tão louca Nunca me veio perpassar à mente Só o quero, o que exalar procuro, São os afetos que minha alma sente 
São essas cismas das insônias minhas Das longas noites que velando eu passo: Quando minha alma s'estremece em dores E a fronte exausta eu reclino ao braço.

$[\ldots]$

E tu, oh mundo, que sorrindo escutas Estes segredos de um sentir sombrio Por Deus, consente que se escapem livres, Não os sufoques com teu rir ímpio. (QUEIROZ, 2015, p. 17-18)

Era difícil para as mulheres reivindicarem para si o lugar de autoria de textos literários. Mesmo assumindo uma atitude transgressora em relação ao lugar social reservado às mulheres na época, Luiza Amélia de Queiroz procura justificar sua ousadia em publicar um livro de poemas como expressão de sua subjetividade. Fica evidente a dificuldade para mulher ascender ao lugar de autoria.

Luiza Amélia de Queiroz menciona na obra Flores Incultas a escritora Maria Amália Vaz de Carvalho e escritores românticos como Gonçalves Dias, Álvares de Azevedo e Casimiro de Abreu. O conhecimento sobre a atuação de outras mulheres no mundo das letras e de ideias que questionavam os papéis legados para as mulheres na sociedade da época deve ter encorajado Luiza Amélia de Queiroz a publicar seus versos. Na escrita de Luiza Amélia de Queiroz predominam o bucolismo, a religiosidade e os temas 
sentimentais sobre a família e os relacionamentos amoroso e conjugal. Mas, também se sobressai um olhar feminino que questiona os lugares sociais reservados às mulheres.

Luiza Amélia de Queiroz assume uma posição transgressora e revela anseios de realização que transcendem as perspectivas que a sociedade prescrevia para as mulheres na época. A admiração de Luiza Amélia por Maria Amália se evidencia no poema "Um êxtase" dedicado à escritora portuguesa. A leitura de textos de Maria Amália de Carvalho pode ter encorajado a poetisa piauiense a publicar seus textos, tendo em vista que a escritora portuguesa defendia a cultura e a instrução como caminhos que levariam a uma emancipação da mulher, inclusive econômica.

Assim, destaca-se que o título Flores Incultas escolhido por Luiza Amélia de Queiroz para seu primeiro livro é carregado de significados simbólicos, considerando-se que as mulheres eram comumente associadas às flores em sua beleza e delicadeza. Eram as mulheres as belas flores incultas da sociedade da época, muitas vezes ornamentadas como bonecas, mas a quem geralmente se negava qualquer instrução de leitura e escrita. Além disso, as flores remetem à primavera, o que permite fazer uma associação entre 
Flores Incultas (1875) de Luiza Amélia de Queiroz e Uma Primavera de Mulher (1867).

Luiza Amélia de Queiroz insere-se no contexto do que se tem denominado de primeira onda feminista na sociedade brasileira, filiando-se aos questionamentos expressos em publicações de redação feminina da época e os quais ela pode ter tido acesso. Além da instrução feminina, muitas escritoras da época também defendiam ideias republicanas e abolicionistas. Nesse sentido destaca-se que Luiza Amélia de Queiroz colaborou com o jornal Telefone (1883 - 1889), que publicava textos favoráveis à República e à abolição da escravatura (DUARTE, 2005; PINHEIRO FILHO, 1997; TELLES, 2000).

Luiza Amélia de Queiroz constituiu-se em uma pioneira que abriu precedentes para atuação feminina nos domínios relacionados à escrita e à publicação de textos no Piauí. Nesse sentido, destaca-se a homenagem feita a essa autora, que teve seu nome escolhido para patrocinar a cadeira vinte e oito da Academia Piauiense de Letras, cujo primeiro ocupante foi Elias de Oliveira. Esta distinção é relevante, se considerarmos que ela é a única escritora cujo nome figura entre os patronos da Academia Piauiense de Letras, que foi criada em 1917. 


\section{MULHERES E IMPRENSA EM TERESINA NAS PRIMEIRAS DÉCADAS DO SÉCULO XX}

Esse estudo destaca a atuação feminina na imprensa em Teresina no início do século XX, capital do Estado do Piauí. Teresina foi a primeira cidade construída de forma planejada no país, a partir da iniciativa do então Presidente da Província do Piauí, Antônio José Conselheiro Saraiva que transferiu a capital do Estado, de Oeiras para a localidade Vila da Mocha em 1852. O nome escolhido para a nova capital foi Teresina, em homenagem a Imperatriz Teresa Cristina, esposa de Dom Pedro II. (VILHENA, 2016)

No início do século $X X$, Teresina era uma cidade jovem quando comparada a outras capitais do país na época. Nessa época, Teresina estava intensificando o seu processo de urbanização em um contexto de modernização e de inovações no que concerne ao comportamento social. Nesse sentido, destaca-se a importação de bens culturais, a realização de bailes lítero-musicais e a difusão de novas formas de comportamento e lazer. Este foi um período de ampliação da presença feminina no espaço público, em atividades relacionadas à educação, ao lazer, à cultura e ao trabalho (CASTELO BRANCO, 2013).

Em relação aos periódicos de redação feminina, destacase em Teresina o jornal Borboleta, que circulou entre 1904 
e 1906, tendo como redatoras Alaíde Burlamaque, Helena Burlamaque e Maria Amélia Rubim. Os discursos feministas da época questionavam a restrição das mulheres ao espaço doméstico e aos papéis sociais atribuídos ao sexo feminino na família. A atuação literária era percebida como uma atividade de reconhecimento intelectual:

A mulher, como todos sabem, deve ser instruída, não só porque a instrução the dá mais realce como também porque a habilita para todos os misteres da vida, para o bom desempenho dos deveres que Ihe são inerentes. Muitos pensam que a mulher deve esmerar-se mais na educação doméstica, eu, porém não penso assim, acho que ela não deve conquistar títulos que não estejam ao seu alcance mais deve estudar e trabalhar muito com o fim de ter certos conhecimentos seguindo assim o exemplo de Maria Amália Vaz de Carvalho, Julia Lopes de Almeida, Ignez de Sabino e tantas outras que têm sabido se impor pela sua vasta ilustração. A instrução é a base da vida, a mulher instruída tem entrada franca em toda parte, e finalmente a instrução é um tesouro que todos devem buscar. (A.B., 1905, p. 1)

As iniciais " $A B$ " podem indicar que a autoria do texto seja de Alaíde Burlamaque, uma das redatoras do jornal. A moral da época recomendava que as mulheres procurassem se comportar de forma discreta e modesta. Esse é um dos fatores associados ao uso de iniciais para assinar textos 
publicados na imprensa. Percebe-se que a autora do texto relacionava a instrução feminina aos deveres considerados inerentes ao sexo feminino, que seriam os papéis de esposa, dona de casa e mãe. O que pode ser compreendido como uma estratégia para apresentar propostas que contribuiriam para a emancipação feminina. As escritoras apropriavam-se desses enunciados para justificar suas reivindicações, utilizando-os para minar as bases de uma formação discursiva que as restringia ao espaço privado, excluindo-as das atividades de reconhecimento intelectual no espaço público (MOREIRA, 2003).

O início do século XX é um período de ampliação do investimento na formação educacional das mulheres em Teresina. Nesse sentido, menciona-se a criação do Colégio Sagrado Coração de Jesus, de caráter confessional e destinado exclusivamente à instrução do sexo feminino. Outra iniciativa do período foi a criação da Escola Normal Oficial, em 1913, que tinha como objetivo privilegiar a instrução de mulheres para atuar no ensino público e privado. Louro (2000) observa que esse processo de inserção das mulheres no magistério estava relacionado a um discurso que atribuía à mulher maior aptidão para o ensino infantil, devido a atributos como meiguice e paciência, que eram considerados naturais ao sexo feminino. 
Destaca-se que atividades relacionadas à educação e ao trabalho possibilitaram o deslocamento da mulher no espaço público. As mulheres instruídas poderiam ter acesso a periódicos voltados para o público feminino, como as revistas Fon-Fon (1907 - 1945) e Revista Feminina (1914 - 1936), que eram mencionadas em anúncios de lojas especializadas na venda de periódicos como a Agência de Revista, situada na cidade de Teresina. Essas publicações contribuíam para difundir imagens de modernidade, progresso e novos comportamentos e papeis femininos na sociedade (ROCHA, 2011).

Pinto (2003) destaca que a mobilização feminina em prol da ampliação de direitos e da participação das mulheres no espaço público logrou notoriedade na sociedade brasileira no final do século XIX e primeiras décadas do século XX. O acesso feminino à instrução e o direito à participação política constituíam as principais pautas do movimento feminista na época. Tratava-se de uma vertente do movimento feminista brasileiro que era representado por mulheres instruídas de classe média e alta.

Observa-se que as discussões sobre o feminismo no Brasil repercutiram na sociedade teresinense. Nesse sentido, menciona-se a presença de textos assinados nos periódicos 
Correio do Piauí e O Piauí na década de 1920, com nomes relacionados ao gênero feminino, como "Acácia", "Berenice", "Bonina", “Dolores", "Eglantine”, “Esmeralda", "Magnólia”, "Sonia" e "Violeta". A identificação por meio de nomes que remetem ao feminino e os temas debatidos são sugestivos de uma autoria feminina. A maioria dos textos defendia a instrução feminina como atividade capaz de ampliar a participação feminina na sociedade do período. Dentre os temas discutidos, menciona-se o feminismo:

[...] o verdadeiro e nobilitante feminismo que eu entendo, não é disputar ao homem, os empregos, as posições políticas, as atribuições sociais; não é adaptar-lhe os trajes, o corte dos cabelos, nem copiar-lhe as maneiras, os hábitos, como se nestas exterioridades residisse a sua proeminência. [...] Cultive a mulher o seu espírito, aprimore seus dons naturais, habilite-se, por uma sólida e bem cuidada instrução, para lutar pela vida, e ter-se-á tornado não livre, mas independente. (VIOLETA, 1926, p. 4)

O feminismo ideal era o que defendia a educação, rejeitando a disputa entre homens e mulheres no mercado de trabalho, na política e a adoção de atitudes e comportamentos que representassem uma "masculinização" da mulher. Essas mulheres estavam preocupadas em se definir diante a variedade de discursos 
feministas e sobre a atuação das mulheres na sociedade da época. Provavelmente eram mulheres instruídas, de alto e médio poder aquisitivo, e que possuíam o hábito de leitura estimulado pela formação escolar.

Não sendo possível precisar a autoria dos textos, percebe-se que as mulheres que utilizavam pseudônimos para discutir sobre o feminismo estavam cientes das transformações que a sociedade brasileira vivenciava no período. Se, por um lado, ocorria uma abertura de espaço para a palavra proferida ou escrita por mulheres, por outro o debate sobre o feminismo realizava-se apenas por meio de pseudônimos. Essas mulheres relutavam em assinar seus textos para evitar críticas que poderiam atingir a elas e a seus familiares (MAGALHÃES, 1998; MORAIS, 2002). Nesse sentido, menciona-se uma advertência de D. Cândida, sogra de Emília Leite Castelo Branco:

Soube que vive estudando e isso já não é mais para você. Escreveu um artigo elogiando muito Celso Pinheiro e isso tem dado o que falar. Minha filha, tenha cuidado, aqui de tudo se comenta. Que é que você quer escrevendo sobre homens ou mesmo mulheres, isso deixe para os poetas. Hoje é só no que se fala, nesse artigo. Você tem o nome de seu marido a zelar. Sei que não fez com má intenção, mas foi um ato reprovável. Deixe esses estudos, cuide de seus enteados e filhos, mais nada. Heitor é porque acha 
tudo bem, mas, francamente, fica muito mal a uma senhora de família andar fazendo artigos de jornal, uma vergonha. (BRANCO, 1983, p. 89-90)

A sogra advertiu Emília Leite Castelo Branco que, como mulher casada, deveria afastar-se das leituras e da publicação de textos nos jornais, ocupando-se dos afazeres domésticos e do cuidado com os filhos e enteados. $\mathrm{O}$ relato indica que a publicação de um texto com uma crítica elogiosa ao literato Celso Pinheiro ${ }^{1}$ gerara comentários na sociedade teresinense. A mulher casada deveria evitar ser alvo de fofocas e maledicências, zelando pela reputação do marido, sobretudo em se tratando de uma família da elite social, econômica, política e cultural do Estado do Piauí.

Emília Leite casou-se aos dezesseis anos com Heitor Castelo Branco (1898-1952), que era advogado e exerceu cargos como: delegado e Chefe de Polícia em Teresina, Diretor da Escola Normal, deputado estadual e deputado federal. Heitor Castelo Branco era filho de Mariano Gil Castelo Branco (1848-1935) e de Cândida Burlamaque Castelo Branco. O genitor de Heitor Castelo Branco, Mariano Gil Castelo Branco foi deputado provincial (18841885) e Vice-Governador do Piauí em 1892; recebeu, nos

1 Celso Pinheiro (1887-1950) foi um dos fundadores da Academia Piauiense de Letras. Poeta, cronista e jornalista. Publicou obras como Almas Irmãs (1907), em coautoria com Antônio Chaves e Zito Baptista, e Flor Incógnita (1912), (ADRIÃO NETO, 1995). 
meses finais do período imperial, o título de Barão de Castelo Branco.

A referência ao sogro através do título de "Barão", na obra Fases do meu passado (1983), ressalta o valor de distinção social do grupo familiar Castelo Branco na sociedade local. Essas relações de distinção social se mantêm através dos matrimônios e, nesse sentido, ressalte-se que Emília Leite era de naturalidade portuguesa e que veio ainda criança morar no Brasil, acompanhando seus pais. A família Castelo Branco é de origem portuguesa; seus primeiros ascendentes chegaram ao Estado do Piauí ainda no período colonial, constituindo-se em uma genealogia antiga de proprietários de terras, com um histórico de representação na elite política, econômica e cultural desse estado. Emília Leite Castelo Branco enfatiza ter sido uma esposa obediente, de maneira que as decisões do marido prevaleciam sobre seus desejos, pois este não aceitava, por exemplo, que ela desenvolvesse trabalhos liberais fora de casa, devendo o sustento familiar ser provido exclusivamente por ele (BRANCO, 1983; BRANDÃO, 1995).

Emília Leite Castelo Branco viveu com o marido no Rio de Janeiro, durante o período em que ele exerceu mandato de deputado federal na legislatura de 1915-1918, e 
posteriormente vieram morar em Teresina. A autora informa que a quantidade de sapatos e as roupas de rendas e sedas caras que possuía chamaram a atenção da família do marido, que a consideravam uma mulher vaidosa e apreciadora de luxo, o que não seria condizente com o ambiente social e a simplicidade das acomodações em que passaria a viver. Segundo a autora, Teresina, na década de 1920, era uma cidade monótona, atrasada, com pessoas maldosas que se ocupavam em observar a vida alheia, para comentar e fazer mexericos. Além disso, exigia-se das mulheres casadas que fossem discretas e econômicas em relação ao orçamento familiar (BRANCO, 1983).

Presume-se que nos centros urbanos de menor densidade populacional o controle sobre o comportamento feminino era vivenciado de maneira mais intensa, por meio da vigilância social, a qual se tornava notória através das fofocas. Essas observações ressaltam as circunstâncias que levavam algumas mulheres a ocultar suas identidades por meio de pseudônimos para discorrer sobre feminismo, em periódicos de Teresina, nas primeiras décadas do século $X X$. Além disso, os discursos antifeministas associavam 0 feminismo ao desordenamento da sociedade e à inversão dos papeis masculinos e femininos, o que contribuía para 
que as mulheres que fossem identificadas como feministas recebessem críticas.

No entanto, a partir do relato memorialista de Emília Leite Castelo Branco percebe-se que havia também entre algumas mulheres a perspectiva de obtenção de reconhecimento social através de habilidades culturais, como a música e a literatura:

Certa ocasião em que fizemos parte de um concerto no nosso colégio mamãe me disse:

- Foste medíocre, uma pena, quem tocou melhor foi Tivica, ela, sim, será uma grande pianista... É o que a senhora mais gosta, não, mamãe? - Falei triste, eu que tudo fazia para agradá-la. Sim, quando menina fugia da casa do meu pai para ouvir as canções que teu avô, pai de teu pai, tocava no violino. Ficava sempre toda emocionada... - Que pena, expressei-me, eu sempre procuro satisfazêla. No entanto, só dou mesmo para escrever e isso a senhora não aprecia, não é? Puxoume a si, abraçou-me e falou francamente: Há minha Lili, se chegares a ser uma escritora, se algum dia fizeres um romance, assim, como esses que gostamos de ler e nos distraem, superarás tudo... Mas essa profissão é, sem dúvida, a mais difícil de todas. No entanto, quem sabe, és inteligente. $E$ rindo a coçarme a cabeça: - Minha filha romancista, que orgulho, que beleza, estejas onde estiveres ou esteja eu morta, baterei palmas lá de entre as nuvens, aplaudindo-te Querida... (BRANCO, 1983, p. 22-23) 
Segundo Emília Leite Castelo Branco, seria um orgulho para a senhora Emerlinda, sua genitora, se a filha se tornasse uma escritora, demonstrando sua capacidade intelectual ao se dedicar à atividade literária, uma profissão considerada difícil e que, dentre outras características, requer habilidade narrativa e criatividade. Percebe-se que novas perspectivas de realização social para as mulheres estavam sendo gestadas no final do século XIX e nas décadas iniciais do século $X X$. Emília Leite Castelo Branco tornou-se mais conhecida como Lili Castelo Branco:

Romancista, cronista, contista e memorialista, nascida em Portugal, na cidade de Fafe e falecida em Teresina (18961993). Filha do comerciante José Gonçalves Leite e Ermelinda de Barros Oliveira. Veio para o Brasil acompanhando seus pais, com apenas dois meses de idade. No Brasil, fixou residência em Belém do Pará, onde recebeu educação primária e secundária. Lili, ainda bem jovem, com apenas doze anos, já mostrava seus pendores literários quando foi premiada em concurso pelo jornal Folha do Norte. (MENDES, 2009, p. 178)

Apenas após tornar-se viúva, Emília Leite Castelo Branco passou a publicar livros, dentre os quais se mencionam: Ermelinda (1959); Os amores de Tomaz (1968); Os mistérios do castelo (1979), Qual será afinal nosso fim? (1981); A misteriosa passageira (1989); e Feliz Arrependimento (1992). Destaque- 
se também que isso ocorreu na segunda metade do século $X X$, um momento em que o deslocamento das fronteiras de gênero tornou-se mais significativo com o aumento da atuação feminina no espaço público e na literatura.

Se, por um lado, havia restrições morais que procuravam controlar a atuação feminina na sociedade, por outro havia também a abertura de novas perspectivas que permitiam a apropriação dos lugares de enunciação pelas mulheres. Nesse sentido, observa-se a participação de alunas e professoras da Escola Normal, publicando crônicas e discursos na imprensa da cidade de Teresina na década de 1920. Menciona-se também a criação do jornal $A$ Normalista em 1927, tendo como redatoras Rosa Cunha e Zilda Santos.

Na década de 1920, destaca-se a criação do Cenáculo Piauiense de Letras (1927-1932), que contava entre seus integrantes com a participação de Júlia Gomes Ferreira, Otilia Carvalho e Silva, Helena Silvia, Zenobia Ribeiro da Silva e Maria lara Borges de Melo. Algumas dessas possuíam relações de parentesco com intelectuais da época. Maria lara Borges de Melo, por exemplo, era filha do literato piauiense Abdias Neves. Observa-se que havia a valorização de um ideal de refinamento cultural entre as famílias de melhor poder aquisitivo da sociedade através de práticas relacionadas à 
música e à literatura. Isto contribuiu para ampliar a atuação feminina nesses segmentos culturais. No entanto, também havia restrições e resistência à ocupação de novos lugares sociais pelas mulheres na sociedade da época.

Ressalta-se que esse foi um período em que as mulheres reivindicavam o reconhecimento de igualdade de aptidão intelectual entre o sexo feminino e o masculino. Esse argumento era essencial para requerer e validar a atuação das mulheres nas diversas instâncias sociais e políticas da sociedade relacionadas ao espaço público.

\section{CONSIDERAÇÕES FINAIS}

A sociedade brasileira no século XIX e décadas iniciais do século $X X$ se alicerçava na concepção de que os papéis femininos e masculinos na sociedade deveriam ser distintos. As atividades relacionadas à intelectualidade foram historicamente reservadas ao sexo masculino. A transformação da concepção de papel feminino na sociedade possibilitou a ampliação da apropriação dos códigos de leitura e escrita pelas mulheres.

O poder aquisitivo foi um aspecto significativo no investimento das famílias na formação educacional e cultural das mulheres. Era necessário formar mulheres aptas a desempenhar melhor seus papéis na família, em 
consonância com fatores de produção e reprodução de distinção social. A mulher deveria ser formada para a cultura dos salões, onde precisava demonstrar refinamento cultural, como um valor simbólico que era agregado à família, à qual representava socialmente.

O lugar social ocupado pelas mulheres e a concepção familiar sobre a conduta feminina e a atuação destas na sociedade poderia favorecer ou colocar empecilhos para que algumas mulheres fizessem uso público da palavra escrita. As mulheres precisaram transpor essas fronteiras de forma gradual, no sentido de ampliar sua atuação na sociedade e de obter reconhecimento social e intelectual.

O final do século XIX e as décadas iniciais do século XX foi um período de transição na sociedade brasileira. É possível observar mudanças, mas também restrições no que concerne à atuação feminina em atividades relacionadas ao espaço público. O investimento da formação educacional e cultural das mulheres possibilitou a formação de um contingente feminino significativo e apto a atuar na imprensa e na literatura no decorrer do século XX.

Compreender a história e promover estudos e releituras das obras dessas mulheres escritoras é uma forma de questionamento dos cânones literários estabelecidos, que 
silenciam sobre a produção literária das escritoras do século XIX. A publicação de textos em obras literárias e periódicos propiciou às mulheres visibilidade intelectual. Além disso, essas mulheres, de forma perspicaz, utilizavam esses instrumentos para defender a ampliação de seus direitos políticos e sociais.

\section{REFERÊNCIAS}

A.B. O adorno da mulher. Borboleta. Teresina, p. 1, 29 dezembro de 1905. ADRIÃO NETO. Dicionário biográfico escritores piauienses de todos os tempos. Teresina: Halley S.A., 1995.

BRANCO, Lili Castelo. Fases do meu passado. Teresina: [s.n], 1983.

BRANDÃO, Tânya Maria Pires. A elite colonial piauiense: família e poder. Teresina: Fundação Cultural Monsenhor Chaves, 1995.

CASTELO BRANCO, Pedro Vilarinho. Famílias e escritas: a prática dos literatos e as relações familiares em Teresina nas primeiras décadas do século XX. 2005.Tese (Doutorado em História) - Universidade Federal de Pernambuco, Recife, 2005.

CASTELO BRANCO, Pedro Vilarinho. Mulheres plurais. 3. ed. Teresina: EDUFPI, 2013.

COSTA FILHO, Alcebíades. A escola do sertão: ensino e sociedade no Piauí, 1850-1889. Teresina: Fundação Cultural Monsenhor Chaves, 2006. CHAVES, Monsenhor Joaquim. Apontamentos biográficos e culturais. Teresina: Fundação Cultural Monsenhor Chaves, 1994.

DUARTE, Constância Lima. Feminismo e Literatura no Brasil. Estudos Avançados. São Paulo,v. 17, n. 49, setembro/dezembro de 2003, p. 151172. Disponível em:http://www.scielo.br/scielo.php?script=sci_arttext\& pid=S010340142003000300010\&lng=pt\&nrm=iso\&tlng=pt. Acesso em: 13 jun. 2020. 
$\mathrm{FALCl}$, Miridam Knox. Mulheres do sertão nordestino. In: DEL PRIORE, Mary. (Org.). História das mulheres no Brasil. 3. ed. São Paulo: Contexto, p. 241-277, 2000.

FOUCAULT, Michel. A Ordem do Discurso: aula inaugural no Collège de France, pronunciada em 2 de dezembro de 1970. 3. ed. São Paulo: Edições Loyola, 1996.

LOURO, Guacira Lopes. Mulheres na sala de aula. In: DEL PRIORE, Mary. (Org.). História das mulheres no Brasil. 3. ed. São Paulo: Contexto, p. 443 - 481, 2000.

MAGALHÃES, Maria do ocorro Rios. Literatura piauiense: horizontes de leitura e crítica literária (1900-1930). Teresina: Fundação Cultural Monsenhor Chaves, 1998.

MENDES, Algemira de Macêdo. Emília Castelo Branco (Lili). In: MENDES, Algemira de Macêdo. ROCHA, Olívia Candeia Lima. ALBUQUERQUE, Marleide Lins de. Antologia de Escritoras Piauienses: século XIX à Contemporaneidade. Teresina: Fundação cultural do Piauí-FUNDAC, Fundação de Apoio cultural do Piauí - FUNDAPI, p. 178-188, 2009. MORAIS, Maria Arisnete Câmara de. Leituras de mulheres no século XIX. Belo Horizonte: Autêntica, 2002.

MOREIRA, Nadilza Martins de Barros. A condição feminina revisitada: Júlia Lopes de Almeida e Kate Chopin. João Pessoa: UFPB, 2003.

PERROT, Michelle. Mulheres públicas. São Paulo: UNESP, 1998.

PINTO, Céli Regina Jardim. Uma história do feminismo no Brasil. São Paulo: Fundação Editora Perseu Abramo, 2003.

QUEIROZ, Luiza Amélia de. Flores Incultas. 2 ed. Teresina: Academia Piauiense de Letras, EDUFPI, 2015.

REGO, Junia Motta Antonaccio do. Dos sertões aos mares: História do comércio e dos comerciantes de Parnaíba (1700-1950). 2010, 304p. Tese (Doutorado em História) - Universidade Federal Fluminense, Niterói, RJ, 2010. ROCHA, Olívia Candeia Lima. Mulheres, escrita e feminismo no Piauí (1875-1950). Teresina: Fundação Cultural Monsenhor Chaves, 2011. 
SCOTT, Joan. Gênero: uma categoria útil de análise histórica. Educação \& Realidade. Porto Alegre: Faculdade de Educação, Universidade Federal do Rio Grande do Sul, v. 20, n. 2, p. 71-99, julho/dezembro de 1995.

SEVCENKO, Nicolau. Literatura como missão: tensões sociais e criação cultural na primeira república. São Paulo: Brasiliense, 1999.

TELLES, Norma. Escritoras, escritos, escrituras. In: DEL PRIORE, Mary. (Org.). História das mulheres no Brasil. 3. ed. São Paulo: Contexto, p. 401 $-442,2000$.

VILHENA, Gustavo Henrique Ramos de. Os fazedores de cidade - uma história da mudança da capital no Piauí (1800-1852). 2016. 272 p. Tese (Doutorado em História). Programa de Pós-Graduação em História, Universidade Federal de Pernambuco, Recife, 2016.

VIOLETA. O feminismo. O Piauí. Vida Social, Teresina, p. 4, 06 abril de 1926.

\section{Olívia Candeia Lima Rocha}

Doutora em História (UNICAMP).

Professora do Campus Senador Helvídio Nunes e Barros (UFPI).

Atua no curso de graduação Licenciatura Plena em História.

Lattes: $\underline{\text { http://lattes.cnpq.br/4787931078683676 }}$

E-mail: candeia09@hotmail.com

ORCID iD: https://orcid.org/0000-0003-0174-5269

\section{Saulo Cunha de Serpa Brandão}

Doutor em Letras (UFPE/ISU), Teoria da Literatura, com duas missões de pós-doutorado concluídas, a primeira no NUPIL/UFSC e a segunda junto ao The New Book Group da University of Washington - Seattle.

Aposentado da UFPI como Professor Titular de literatura e atualmente Professor Adjunto A na UFRPE.

Lattes: http://lattes.cnpq.br/3857487715990801

E-mail: brandaosaulo@yahoo.com

ORCID iD: http://orcid.org/0000-0002-5091-2804 